IGUSABDER, 14 (2021): 241-257

\title{
Tip 2 Diyabetli Hastaların Beslenme Bilgi Düzeylerinin Ölçülmesi
}

\author{
Ayşe Huri ÖZKARABULUT*, Mahruk RASHIDI**, Gülay YILDIRIM****
}

\section{$\ddot{0} \mathbf{z}$}

Amaç: $\mathrm{Bu}$ araştırmanın amacı diyabet polikliniğine gelen Tip 2 diyabetli hastaların beslenme bilgi düzeylerini belirlemektir.

Yöntem: Tanımlayıcı tipteki araştırma gerekli izinler alınarak eğitim ve araştırma hastanelerinin, diyabet polikliniğine başvuran toplam 100 hasta ile yürütüldü. Veriler hastaların sosyodemografik, tanıtıcı özelliklerini içeren 27 soru ve beslenme bilgi düzeylerini ölçen 20 soru olmak üzere toplam 47 sorudan oluşan yarı yapılandırılmış bilgi formuyla toplandı. Verilerin analizi bilgisayar ortamında SPSS programı kullanılarak yapıldı.

Bulgular: Tip 2 diyabetli hastaların beslenme bilgi düzeyleri 9,45 $\pm 3,96$ olarak saptandı. Beslenme eğitimi alan ve Beden Kitle İndeksi (BKİ) normal olan hastaların beslenme bilgi düzeyleri daha yüksekti ( $\mathrm{p}<, 001 ; \mathrm{p}<, 01$ ). Çalışmada düzenli insülin direnci testi, kan şekeri takibi, HbA1c testi yaptıranların, düzenli yaptırmayanlara göre beslenme bilgi düzeyleri daha yüksekti ( $\mathrm{p}<, 05 ; \mathrm{p}<, 001 ; \mathrm{p}<, 001)$. Ayrıca insülin direnci değeri normal olanların, son ölçülen tokluk şekeri

\footnotetext{
Özgün Araştırma Makalesi (Original Research Article)

Geliş / Received: 06.04.2021 \& Kabul / Accepted: 18.05.2021

DOI: https://doi.org/10.38079/igusabder.910150

${ }^{*}$ Dr. Öğr. Üyesi, İstanbul Gelişim Üniversitesi, Sağlık Bilimleri Fakültesi, Beslenme ve Diyetetik Bölümü, İstanbul, Türkiye, E-posta: ahozkarabulut@gelisim.edu.tr ORCID https://orcid.org/0000-0002-4977-6753

*** Dr. Öğr. Üyesi, İstanbul Gelişim Üniversitesi, Sağlık Bilimleri Fakültesi, Hemşirelik Bölümü, İstanbul, Türkiye, E-posta: mrashidi@gelisim.edu.tr ORCID https://orcid.org/0000-0002664.5-2427

**** Öğr. Gör, İstanbul Gelişim Üniversitesi, Sağlık Bilimleri Fakültesi, Hemşirelik Bölümü, İstanbul, Türkiye, E-posta: gyildirim@gelisim.edu.tr ORCID https://orcid.org/o0oo-00029589-7134
}

ETİK BİLDİRIM: İstanbul Gelişim Üniversitesi Etik Kurulu’nun 20.06.2017 tarih ve 201714 sayll toplantısinda 12(1) maddesi ile etik kurul onayı alındr. 
$200 \mathrm{mg} / \mathrm{dl}$ 'nin altında ve HbA1c değeri \% 6,5 altında olanların, diyabet komplikasyonları ve diyabetik ayak hakkında bilgileri olanların beslenme bilgi düzeyleri daha yüksekti $(\mathrm{p}<, 05)$.

Sonuç: Sonuç olarak diyabetli hastaların bilgi düzeylerinin orta düzeyde olduğu saptandı. Diyabet eğitimlerinin beslenme bilgi düzeyini arttırdığı, düzenli takibi ve metabolik kontrolü sağladığı görüldü. Tip 2 diyabetli hastaların diyabetle ilgili beslenme bilgilerini arttırmak hastaların tetkiklerini düzenli yaptırmalarını, metabolik kontrolü sağlamalarını ve yaşam kalitelerini arttırmayı sağlayacaktır.

Anahtar Kelimeler: Tip 2 diyabet, hasta, beslenme, bilgi düzeyi.

\title{
Measuring Nutritional Knowledge Levels of Diabetes Patients Type 2
}

\begin{abstract}
Aim: The aim of this study is to determine the nutritional knowledge of patients with Type 2 diabetes who come to diabetes outpatient clinics.
\end{abstract}

Method: The descriptive study was conducted with a total of 100 patients who came to the diabetes outpatient clinics of training and research hospitals with the necessary permissions. The data were collected using a semi-structured information form consisting of 27 questions including sociodemographic and introductory characteristics of the patients, and 20 questions measuring nutritional knowledge levels, and a total of 47 questions. The analysis of the data was done using the SPSS program on the computer.

Results: Nutritional knowledge level of patients with type 2 diabetes was found to be 9,45 $\pm 3,96$. The nutritional knowledge levels of the patients who received nutrition training and had normal BMI were higher $(\mathrm{p}<, 001 ; \mathrm{p}<, 01)$. In the study, those who had regular insulin resistance testing, blood glucose monitoring, and $\mathrm{HbA1C}$ tests had higher nutritional knowledge than those who did not regularly ( $\mathrm{p}<, 05 ; \mathrm{p}<, 001 ; \mathrm{p}<, 001)$. In addition, those with normal insulin resistance values, those with last measured postprandial glucose below $200 \mathrm{mg} / \mathrm{dl}$ and an HbA1c value below 6.5\%, and those who had information about diabetes complications and diabetic foot had higher nutritional knowledge $(\mathrm{p}<.05)$.

Conclusion: As a result, it was found that the knowledge level of diabetic patients was at a moderate level. It was observed that diabetes education increased the level of nutritional knowledge, provided regular follow-up and metabolic control. Increasing the nutritional knowledge of patients with type 2 diabetes will enable them to have regular examinations, provide metabolic control and increase their quality of life.

Keywords: Type 2 diabetes, patient, nutrition, knowledge level. 


\section{Giriş}

Diabetes Mellitus, pankreasın beta hücrelerinden salgılanan ve kan şekerini düzenleyen insülin hormonunun tamamen veya kısmen yetersizliği sonucu ortaya çıkan başta karbonhidrat metabolizması olmak üzere diğer metabolizmalarında bozulmasına neden olan, hiperglisemi ile seyreden ve komplikasyonları olan kronik bir hastalıktır ${ }^{1,2}$. Dünyada diyabet prevelansı yetişkin nüfusta \%4,7'den \%8,5’e yükselmiştir. Diyabet 2012 yılında dünyada 1,5 milyon ölüme neden olmuştur. Tip 2 diyabet daha önceleri orta yaşlı ve yaşlı kişilerde görülüyorken, zaman içerisinde çocuklarda ve gençlerde de görülme sıklığı artmıştır3. Türkiye Diyabet Epidemiyoloji Çalışması (TURDEP)-2 verilerine göre diyabet sıklığı \%13,7 olarak tespit edilmiştir. TURDEP 1 verilerinde \%7,2 olan oran 12 yılda hızla artmıştır. Bu çalışmaya göre, diyabetlilerin \%32'si hastalıklarının farkında değildir. TURDEP çalışmalarına göre; diyabet kadınlarda ve kentsel bölgelerde yaşayanlarda daha sıktır, ayrıca diyabet riski yaşlanma, obezite, hipertansiyon, ailede diyabet varlı̆̆ı, eğitimsizlik, gelir düzeyi ve alışkanlıklarla ilişkili bulunmuştur4. Türkiye'de ve dünyada, artan prevalans ve mortalite nedeniyle diyabet yönetimi giderek önem kazanmıştır. Sağlıklı bir beslenme alışkanlığı ve ilaç tedavisi diyabet yönetiminin temelini oluşturur. American Diabetes Association (ADA) diyabetin tıbbi beslenme tedavisinde, diyabetli birey eğitim, kendi kendini yönetim ve tedavi planında sağlık kuruluşlarından yardım almalıdır. Diyabette beslenme eğitiminde verilen temel beslenme bilgileri, eğitimin sıklı̆̆ı, eğitim süresi, kullanılan materyaller gibi etkenler hedeflere ulaşmada yardımcı olabilir ve farklılıklar yaratabilir. Eğitimlerde diyabetli hastalar için çok önemli olan glisemik indeks ve etki eden etmenler anlatılmalıdır5,6.

Glisemik indeks (GI) 1981'de karbonhidrat içeren yiyeceklerin sınıflandırılması için alternatif bir sistem olarak önerilmiştir. O tarihten bu yana, glisemik indeksin klinik önemi tartışma konusu olmaya devam etmektedir ${ }^{1}$. GI değerlerine göre yiyeceklerin sınıflandırılması GI değerine göre; düşük GI’li yiyecekler: GI<55, orta GI'li yiyecekler: GI =55-70, yüksek GI’li yiyecekler: GI > 70 olmak üzere üç grupta toplanır7. Gıdaların fiziksel formu; bazı yiyeceklerin partikül büyüklüğünün değiştirilmesi GI’larını değiştirir3. Örneğin, patatesin sıcak ve püre halinde yenildiğinde GI’i yüksek, haşlandıktan sonra, bir gece buzdolabında bekletildiğinde GI’i \%25 azalmaktadır5. Besinlerin yapısında yer alan nişasta türleri; nişastadaki amiloz/amilopektin oranı önemlidir. Bir yiyecekte amiloz oranının yükselmesi GI’i düşürür. Amilozun $\alpha$-amilazla 
hidrolizi sonucu daha az sayıda glikoz oluşur, bu sayede GI’i düşüktür. Baklagillerde amiloz oranı yüksektir, dolayısıyla GI düşüktür. Buğday ununda ise amilopektin yüksek olduğu için GI'de yüksektir. Farklı pirinç türleri farklı GI’lere sahip olabilir. Pirinç GI'si, tahıllardaki amilozun amilopektine oranından etkilenir ${ }^{6}$.

Besinin emilim ve sindirimi; arttıkça GI'si yükselir. Emilim oranları çeşitli yiyecekler için farklıdır. Örneğin; 2 g karbonhidratın emilim oranı ekmekte \%27, mercimekte \%15 ve soya fasulyesinde \%6 olarak bulunmuştur. GI ve ağırlık kontrolü üzerine yapılan uzun vadeli araştırmalar arttıkça, yüksek oranda rafine tahıllar yerine tam tahıl ve düşük GI tahılların tüketimi, fazla yemeyi önlemeye yardımcı olabilecektir. Glisemik indeksi yüksek olan yiyeceklerin sağlığa zararlı olduğu ve diyabetli bireylere bu yiyeceklerden uzak durmaları gerektiği söylenmelidir8 ${ }^{8}$.

Öğün sayıları ve ara öğünlerin önemi özellikle insülin kullanan hastalara anlatılmalıdır. Hipoglisemi diyabetin en ölümcül komplikasyonudur. Ara öğünlerdeki besin seçiminde de GI dikkat edilmelidir. Araştırmalar diyabet, kalp-damar hastalıkları ve şişmanlık gibi kronik hastalık risklerinde düşük glisemik indeksin olumlu etkileri olduğunu göstermiştir5,9,10. Düşük glisemik indeksli diyetin yararlarından bazıları; açlık kan şekeri kontrolü sağlaması, insülin direncini azaltması, kalp hastalıklarından koruması, Tip 2 diyabet riskini azaltması, vücut ağırlığı kontrolüne yardımcı olması, daha az enerji alınmasını sağlaması olarak sayılabilir ${ }^{11}$.

Bu çalışmada amaç diyabetli bireylerin beslenme bilgi düzeylerini ölçmek ve diyabet polikliniğine gelen hastalara daha fazla yardımcı olmaktır.

\section{Gereç ve Yöntem}

Araştırmanın Amacı: Tanımlayıcı tipteki araştırmanın amacı diyabet polikliniklerine başvuran hastaların beslenme bilgi düzeylerini belirlemektir.

Araştırmanın Yapıldı̆̆ı Yer: $\mathrm{Bu}$ çalışma diyabetli hastalara daha kolay ulaşılabileceği için Haseki Eğitim ve Araştırma Hastanesi diyabet polikliniğine gelen hastalara ve Antalya'da bir devlet hastanesinde diyabet polikliniğine başvuran hastalar üzerinde uygulandı. Toplam 100 diyabetli hastanın katılımı ile çalışma gerçekleştirildi. İstanbul Gelişim Üniversitesi Etik Kurulu'nun 20.06.2017 tarih ve 201714 sayll toplantısında 12(1) maddesi ile etik kurul onayı alındı. 
Araştırmanın Evren ve Örneklemi: Bu çalışmanın evreni araştırmanın yapıldı̆̆ı tarihlerde eğitim ve araştırma hastanelerinin diyabet polikliniklerine başvuran Tip 2 diyabetli tüm hastalar, örneklemi ise çalışmanın yapıldı̆̆ı tarihler arasında diyabet polikliniğine başvurmuş, çalışmaya katılmayı kabul eden 100 hasta oluşturdu.

Veri Toplama Araçları: Veri toplama aracı olarak toplam 47 sorudan oluşan yarı yapılandırılmış bilgi formu kullanıldı. Bu formda; sosyodemografik sorular, hasta ve hastalık ile ilgili özellikler ve diyabetle ilgili beslenme bilgilerini ölçen sorular bulunmaktadır.

Veri Toplama Yöntemi: Veriler toplanmadan önce hastalara çalışma hakkında bilgi verildi. Sözlü ve yazılı gönüllü onamları alındı. Hastalar ile birebir görüşmeler yapılarak yarı yapılanmış bilgi formu dolduruldu. Bu formunda Tip 2 diyabetli hastalara beslenme alışkanlıklarını sorgulayan ve beslenme bilgilerini ölçen toplam 20 soru soruldu. Sorularda doğru seçeneği işaretleyen hastalara "1" puan, yanlış seçeneği işaretleyen hastalara ise "o" puan verildi. Sorulara verilen puanlar toplanarak hastaların beslenme bilgi düzeyleri ölçüldü. Sorulara verilen cevapların toplamı o-20 arasındadır.

Verilerin Analizi: Araştırmanın veri analizi SPSS 22.0 paket programı kullanılarak yapıldı. İstatistiksel analiz olarak; yüzdelik dağılım, ortalama, standart sapma, OneSample Kolmogorov-Smirnov, Independent-Samples T Testi Ve One-Way Anova testi kullanıldı. Sonuçlar \%95 güven aralığında, p<0,05 anlamlılık düzeyinde değerlendirildi. Araştırmanın Etik Yönü: Çalışmanın yapılabilmesi için gerekli izinler alındı. Çalışmaya katılanlardan kimlik bilgileri istenmedi, gönüllü onam formları alındı

\section{Bulgular}

Araştırmaya katılan diyabetli hastaların sosyodemografik özelliklerinin dağılımı tablo 1. de verilmiştir. Katılımcıların \%67’si kadın, \%37’si 45-54 yaş aralığında, \%51’i ilkokul, \%49’u ev hanımı, \%85’i evli ve \%68'nin geliri giderine eşittir (Tablo 1). 
Tablo 1. Diyabetli hastaların sosyodemografik özelliklerinin dağılımı $(N=100)$

\begin{tabular}{|c|c|c|c|}
\hline \multicolumn{2}{|c|}{ Sosyo-Demografik Özellikler } & \multirow{3}{*}{$\begin{array}{c}\mathbf{n} \\
67 \\
33\end{array}$} & \multirow{3}{*}{$\begin{array}{l}\mathbf{\%} \\
67 \\
33\end{array}$} \\
\hline Cincivet & Kadın & & \\
\hline 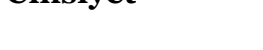 & Erkek & & \\
\hline \multirow{4}{*}{ Yaş } & $35-44$ & 17 & 17 \\
\hline & $45-54$ & 37 & 37 \\
\hline & $55-64$ & 26 & 26 \\
\hline & 65 üstü & 20 & 20 \\
\hline \multirow{5}{*}{ Eğitim Durumu } & Okuryazar değil & 5 & 5 \\
\hline & İlkokul & 51 & 51 \\
\hline & Ortaokul & 15 & 15 \\
\hline & Lise & 14 & 14 \\
\hline & Üniversite & 15 & 15 \\
\hline \multirow{5}{*}{ Meslek } & Memur & 10 & 10 \\
\hline & İşci & 9 & 9 \\
\hline & Serbest meslek & 17 & 17 \\
\hline & Ev hanımı & 49 & 49 \\
\hline & Emekli & 15 & 15 \\
\hline \multirow{2}{*}{ Medeni Durum } & Evli & 85 & 85 \\
\hline & Bekâr & 15 & 15 \\
\hline \multirow{3}{*}{ Gelir Durumu } & Gelir gidere eşit & 68 & 68 \\
\hline & Gelir giderden fazla & 2 & 2 \\
\hline & Gelir giderden az & 30 & 30 \\
\hline \multicolumn{2}{|l|}{ TOPLAM } & 100 & 100 \\
\hline
\end{tabular}

Hastaların \%41'nin diyabet süresi 1-4 yıl, \%54'nün diyabet öyküsü bulunmakta, \%63’nün başka bir hastalığının olmadığı ve \% 46’sının fazla kilolu olduğu saptandı. Diyabetli hastaların \%74'nün beslenme eğitimi aldı̆̆ı, \%58'nin beslenme eğitimini diyetisyenden aldığı ve beslenme eğitimi alanların \%39'nun bu eğitimi uygulamadı̆̆ı tespit edildi. Hastaların \% 66'sının insülin direnci testi yaptırdı̆̆ı, \%56'sının insülin direnci testi değerinin yüksek olduğu, \%47'sinin kan şekerini düzensiz ölçtüğü, \%85'nin son ölçülen açlık kan şekerinin 126 mg/dl'nin üstünde olduğu, \%62'sinin son ölçülen tokluk kan şekerinin 200mg/dl'nin altında olduğu ve \%76'sının son ölçülen HbA1C'sinin normal 
sınırların üstünde olduğu belirlendi. Hastaların \%36'sının diyabet tedavi şekli tıbbi beslenme ile birlikte insülin tedavisidir. Hastaların \%58'nin diyabet komplikasyonlarını bildiği, \%64'nün düzenli HbA1C testini, kolesterol düzeylerini kontrol ettirdikleri \%76’sının düzenli göz kontrollerini, \%77'sinin düzenli kalp ve böbrek kontrollerini yaptırmadığı, \%58'nin diyabetik ayağı bilmediği, \% 64'nün hipoglisemi yaşadığı tespit edildi (Tablo 2).

Tablo 2. Hastaların diyabetle ilgili özelliklerinin dağılımı $(\mathrm{N}=100)$

\begin{tabular}{|c|c|c|c|}
\hline \multicolumn{2}{|l|}{ Tanıtıcı Özellikler } & \multirow{2}{*}{$\begin{array}{c}\mathrm{n} \\
11\end{array}$} & \multirow{2}{*}{\begin{tabular}{|l}
$\%$ \\
11
\end{tabular}} \\
\hline \multirow{4}{*}{ Diyabet süresi } & 1 yll önce & & \\
\hline & 1-4 yl & 41 & 41 \\
\hline & $5-9$ yll & 26 & 26 \\
\hline & 10 ve üstü & 22 & 22 \\
\hline \multirow{2}{*}{ Ailede diyabet öyküsü } & Var & 54 & 54 \\
\hline & Yok & 46 & 46 \\
\hline \multirow{2}{*}{ Başka bir hastalık varlığı } & Evet & 37 & 37 \\
\hline & Hayır & 63 & 63 \\
\hline \multirow{3}{*}{ Beden Kitle İndeksi } & $18,5-24,9$ & 13 & 13 \\
\hline & $25-29,9$ & 46 & 46 \\
\hline & $\geq 30$ & 41 & 41 \\
\hline \multirow{2}{*}{ Beslenme eğitimi alma durumu } & Evet & 74 & 74 \\
\hline & Hayır & 26 & 26 \\
\hline \multirow{3}{*}{ Beslenme eğitimini aldığı kişi } & Doktor & 16 & 16 \\
\hline & Diyetisyen & 58 & 58 \\
\hline & Eğitim almayanlar & 26 & 26 \\
\hline \multirow{2}{*}{ Beslenme eğitimini uygulama durumu } & Evet & 35 & 35 \\
\hline & Hayır & 39 & 39 \\
\hline \multirow{2}{*}{ İnsülin direnci testi } & Yapıldı & 66 & 66 \\
\hline & Yapılmadı & 34 & 34 \\
\hline \multirow{2}{*}{ İnsülin direnci değerleri } & Normal $(<2,5)$ & 10 & 10 \\
\hline & Yüksek $(>2,5)$ & 56 & 56 \\
\hline \multirow{3}{*}{ Kan şekerini ölçme sıklığı } & Günlük & 20 & 20 \\
\hline & Haftada 1-2 kez & 33 & 33 \\
\hline & Düzensiz & 47 & 47 \\
\hline
\end{tabular}




\begin{tabular}{|c|c|c|c|}
\hline \multirow{2}{*}{ Son ölçülen açlık kan şekeri } & $<126 \mathrm{mg} / \mathrm{dl}$ & 15 & 15 \\
\hline & $>126 \mathrm{mg} / \mathrm{dl}$ & 85 & 85 \\
\hline \multirow{2}{*}{ Son ölçülen tokluk kan şekeri } & $<200 \mathrm{mg} / \mathrm{dl}$ & 62 & 62 \\
\hline & $>200 \mathrm{mg} / \mathrm{dl}$ & 38 & 38 \\
\hline \multirow{2}{*}{ Son ölçülen HbA1C değeri } & $<6,5$ & 24 & 24 \\
\hline & $>6,5$ & 76 & 76 \\
\hline \multirow{4}{*}{ Diyabet tedavi şekli } & Tibbi beslenme tedavisi & 11 & 11 \\
\hline & $\begin{array}{l}\text { Tibbi beslenme tedavisi + Oral } \\
\text { antidiyabetik }\end{array}$ & 34 & 34 \\
\hline & Tibbi beslenme tedavisi + İnsülin & 36 & 36 \\
\hline & $\begin{array}{l}\text { Tibbi beslenme tedavisi + Oral } \\
\text { antidiyabetik + İnsülin }\end{array}$ & 19 & 19 \\
\hline \multirow{2}{*}{$\begin{array}{l}\text { Diyabet komplikasyonlarını bilme } \\
\text { durumu }\end{array}$} & Evet & 58 & 58 \\
\hline & Hayır & 42 & 42 \\
\hline \multirow{2}{*}{ Düzenli HbA1 C testi yaptırma durumu } & Evet & 64 & 64 \\
\hline & Hayır & 36 & 36 \\
\hline \multirow{2}{*}{$\begin{array}{l}\text { Düzenli kolesterol düzeylerini kontrol } \\
\text { etme durumu }\end{array}$} & Evet & 64 & 64 \\
\hline & Hayır & 36 & 36 \\
\hline \multirow{2}{*}{$\begin{array}{l}\text { Düzenli göz kontrollerini yaptırma } \\
\text { durumu }\end{array}$} & Evet & 24 & 24 \\
\hline & Hayır & 76 & 76 \\
\hline \multirow{2}{*}{$\begin{array}{l}\text { Düzenli kalp, böbrek kontrollerini } \\
\text { yaptırma durumu }\end{array}$} & Evet & 23 & 23 \\
\hline & Hayır & 77 & 77 \\
\hline \multirow{2}{*}{ Diyabetik ayak } & Biliniyor & 42 & 42 \\
\hline & Bilinmiyor & 58 & 58 \\
\hline \multirow{2}{*}{ Hipoglisemi yaşama durumu } & Evet & 64 & 64 \\
\hline & Hayır & 36 & 36 \\
\hline \multicolumn{2}{|l|}{ TOPLAM } & 100 & 100 \\
\hline
\end{tabular}

Diyabetli hastaların beslenme alışkanlıklarını ve beslenme bilgilerini ölçen sorulara verdikleri cevaplar incelendiğinde, sorulardan alınan toplam puan ortalamasının 9,45 $\pm 3,96$ olduğu saptandı (Tablo 3). 
Tablo 3. Beslenme alışkanlıkları ve beslenme bilgileri ile ilgili sorulara verilen cevapların ortalaması

\begin{tabular}{|c|c|c|c|c|}
\hline $\begin{array}{l}\text { Beslenme Alışkanlıkları ve Beslenme Bilgileri ile Ílgili } \\
\text { Sorular }\end{array}$ & Ort & $\pm \mathbf{S S}$ & Min. & Max. \\
\hline 1. Günlük ana ve ara öğün sayısı & 0,71 & $\pm 0,46$ & O & 1 \\
\hline 2. Ana öğünlerini düzenli tüketme & 0,77 & $\pm 0,42$ & $\mathrm{O}$ & 1 \\
\hline 3. Ara öğünlerini düzenli tüketme & 0,41 & $\pm 0,49$ & O & 1 \\
\hline 4. Öğünlerin genellikle tüketildiği yer & 0,98 & $\pm 0,14$ & o & 1 \\
\hline 5. Beslenmede önemli besin gruplarını bilme & 0,33 & $\pm 0,47$ & $\mathrm{O}$ & 1 \\
\hline 6. Tercih edilen ekmek türü & 0,52 & $\pm 0,50$ & O & 1 \\
\hline 7. Ekmek yerine geçenleri tüketince ekmeği azaltma durumu & 0,48 & $\pm 0,50$ & o & 1 \\
\hline 8. Pirinç pilavı yerine bulguru tercih etme durumu & 0,63 & $\pm 0,48$ & $\mathrm{O}$ & 1 \\
\hline 9. Tercih edilen pişirme yöntemi & 0,80 & $\pm 0,40$ & O & 1 \\
\hline 10. Süt, yoğurt gıdalarında tam yağlı, yarım yağlı tercihi & 0,17 & $\pm 0,37$ & $\mathrm{O}$ & 1 \\
\hline 11. Prebiyotik yoğurt, kefir tüketme durumu & 0,38 & $\pm 0,49$ & o & 1 \\
\hline 12. Toz probiyotik kullanma & 0,05 & $\pm 0,22$ & O & 1 \\
\hline 13. Glisemik indeksi bilme & 0,21 & $\pm 0,40$ & $\mathrm{O}$ & 1 \\
\hline 14. Çay, kahve tüketirken şeker kullanma & 0,56 & $\pm 0,49$ & $\mathrm{O}$ & 1 \\
\hline 15. Şeker yerine tatlandırıcı kullanma & 0,18 & $\pm 0,39$ & O & 1 \\
\hline 16. Meyve sebze tüketirken kabukları soyma & 0,24 & $\pm 0,42$ & O & 1 \\
\hline 17. Günlük su tüketimi & 0,26 & $\pm 0,44$ & O & 1 \\
\hline 18. Sigara Kullanımı & 0,69 & $\pm 0,46$ & $\mathrm{O}$ & 1 \\
\hline 19. Alkol Kullanımı & 0,91 & $\pm 0,29$ & O & 1 \\
\hline 20. Düzenli egzersiz yapma durumu & 0,17 & $\pm 0,38$ & $\mathrm{O}$ & 1 \\
\hline Toplam puan & 9,45 & $\pm 3,96$ & 3 & 18 \\
\hline \multicolumn{5}{|c|}{ Sorularin genel ortalamasi $=9,45$} \\
\hline
\end{tabular}

Ort: Ortalama, SS: Standart sapma, Min: Minumum, Maks: Maksimum

Beslenme bilgi düzeylerinin; diyabetli kadın hastalarda erkek hastalara, yaş aralığı 3544 olan hastaların diğer yaş grubu hastalara, eğitim durumu üniversite olan hastaların ilkokul ve lise olanlara, mesleği memur olan hastaların diğer meslek gruplarına ve gelir gideri eşit olan hastaların geliri giderinden az olan hastalara göre daha yüksek olduğu saptandı (sırasiyla; $\mathrm{p}<, 001 ; \mathrm{p}<, 05 ; \mathrm{p}<, 01 ; \mathrm{p}<, 001 ; \mathrm{p}<, 01$ ) (Tablo 4). 
Tablo 4. Hastaların sosyodemografik özelliklerinin beslenme bilgi düzeyi ile karşılaştırılması $(\mathrm{N}=100)$

\begin{tabular}{|c|c|c|c|c|c|}
\hline \multicolumn{2}{|c|}{ Sosyo-Demografik Özellikler } & \multirow{3}{*}{$\begin{array}{l}\mathbf{n} \\
67\end{array}$} & \multicolumn{2}{|c|}{$\begin{array}{c}\text { Beslenme Alışkanlıkları ve } \\
\text { Beslenme Bilgileri ile İlgili } \\
\text { Soruların Toplam Puanı }\end{array}$} & \multirow[t]{2}{*}{$\mathbf{p}$} \\
\hline & & & Ort \pm SS & $\mathbf{t} / \mathbf{F}$ & \\
\hline \multirow{2}{*}{ Cinsiyet } & Kadın & & $10,42 \pm 3,4$ & \multirow{2}{*}{$t=3,701$} & \multirow{2}{*}{, $\mathbf{0 0 0}$} \\
\hline & Erkek & 33 & $7,48 \pm 4,2$ & & \\
\hline & & & & Independe & les TTest \\
\hline \multirow{4}{*}{ Yaş } & $35-44$ & 17 & $12,12 \pm 4,4$ & \multirow{4}{*}{$\mathrm{F}=3,557$} & \multirow{4}{*}{, $\mathbf{0 1 7}$} \\
\hline & $45-54$ & 37 & $9,27 \pm 2,8$ & & \\
\hline & $55-64$ & 26 & $8,69 \pm 5,1$ & & \\
\hline & 65 üstü & 20 & $8,50 \pm 2,9$ & & \\
\hline \multirow{5}{*}{ Ĕgitim Durumu } & Okuryazar değil & 5 & $8,80 \pm 4,1$ & \multirow{5}{*}{$\mathrm{F}=5,129$} & \multirow{5}{*}{, $\mathbf{0 0 1}$} \\
\hline & İlkokul & 51 & $8,52 \pm 3,0$ & & \\
\hline & Ortaokul & 15 & $10,00 \pm 3,9$ & & \\
\hline & Lise & 14 & $8,43 \pm 4,8$ & & \\
\hline & Üniversite & 15 & $13,20 \pm 3,6$ & & \\
\hline \multirow{5}{*}{ Meslek } & Memur & 10 & $14,50 \pm 2,6$ & \multirow{5}{*}{$\mathrm{F}=8,164$} & \multirow{5}{*}{, $\mathbf{0 0 0}$} \\
\hline & İşci & 9 & $6,44 \pm 2,9$ & & \\
\hline & Serbest meslek & 17 & $8,24 \pm 4,5$ & & \\
\hline & Ev hanımı & 49 & $9,82 \pm 2,5$ & & \\
\hline & Emekli & 15 & $8,07 \pm 5,4$ & & \\
\hline & & & & \multicolumn{2}{|c|}{ One-Way Anova Test } \\
\hline \multirow{2}{*}{ Medeni Durum } & Evli & 85 & $9,41 \pm 3,9$ & \multirow{2}{*}{$t=-0,229$} & \multirow{2}{*}{,819 } \\
\hline & Bekâr & 15 & $9,67 \pm 4,2$ & & \\
\hline & & & & \multicolumn{2}{|c|}{ Independent-Samples T Test } \\
\hline \multirow{3}{*}{ Gelir Durumu } & Gelir gidere eşit & 68 & $10,41 \pm 3,9$ & \multirow{3}{*}{$\mathrm{F}=7,041$} & \multirow{3}{*}{,oo1 } \\
\hline & Gelir giderden fazla & 2 & $7,50 \pm 3,5$ & & \\
\hline & Gelir giderden az & 30 & $7,40 \pm 3,4$ & & \\
\hline & & & & $\mathrm{Or}$ & nova Test \\
\hline
\end{tabular}

Ort: Ortalama, SS: Standart sapma

Beslenme bilgi düzeyleri; başka bir hastalığı olmayanların olanlara, BKİ normal olan hastaların kilolu ve obez hastalara göre daha yüksekti (sırasıyla; p<,o01; p<,o1). Beslenme eğitimi alan hastaların beslenme eğitimi almayanlara, beslenme eğitimini diyetisyenden alanların eğitimi doktordan alanlara ve aldığı beslenme eğitimini uygulayan hastaların eğitimi uygulamayanlara göre beslenme bilgi düzeyleri daha yüksekti (sırasıyla; $\mathrm{p}<, 001 ; \mathrm{p}<, 01 ; \mathrm{p}<, 001$ ). Beslenme bilgi düzeyleri; insülin direnci 
testi yaptıranların yaptırmayanlara, insülin direnci değeri normal olanların sınırların üzerinde olanlara göre daha yüksekti (p<,05). Kan şekerini günlük ve haftada 1-2 kez ölçenlerin düzenli ölçmeyenlere, son ölçülen tokluk şekeri 200mg/dl'nin altında olanların bu değerin üzerinde olanlara, son ölçülen $\mathrm{HbA1C}$ değeri\% 6,5 altında olanların bu değerin üzerinde olanlara göre beslenme bilgi düzeyleri daha yüksekti (sırasıyla; $\mathrm{p}<, 001, \mathrm{p}<, 05 ; \mathrm{p}<, 05)$. Diyabetik tedavi şekli tıbbi beslenme ile birlikte oral antidiyabetik olan hastaların beslenme bilgi düzeyleri tedavi şekli tıbbi beslenme ile birlikte insülin olan ve tıbbi beslenme ile birlikte oral antidiyabetik, insülin olanlara göre daha yüksek olarak saptandı $(\mathrm{p}<, 05)$. Diyabetik komplikasyonları bilenlerin bilmeyenlere, düzenli $\mathrm{HbA1C}$ testi yaptıranların yaptırmayanlara, diyabetik ayağı bilenlerin bilmeyenlere göre beslenme bilgi düzeyleri daha yüksekti (sırasıyla; p<,o5; $\mathrm{p}<$, o01; $\mathrm{p}<, 05$ ) (Tablo 5).

Tablo 5. Hastaların diyabetle ilgili özelliklerinin beslenme bilgi düzeyi ile karşılaştırılması

\begin{tabular}{|c|c|c|c|c|c|}
\hline \multirow{2}{*}{\multicolumn{2}{|c|}{ Diyabetle İlgili Özellikler }} & \multirow[t]{2}{*}{$\mathbf{n}$} & \multicolumn{2}{|c|}{$\begin{array}{l}\text { Beslenme } \\
\text { Alışkanlıkları ve } \\
\text { Beslenme Bilgileri ile } \\
\text { İlgili Soruların Toplam } \\
\text { Puanı }\end{array}$} & \multirow[t]{2}{*}{$\mathbf{p}$} \\
\hline & & & Ort \pm SS & $\mathbf{t} / \mathbf{F}$ & \\
\hline Başka bir hastalık varlığı & $\begin{array}{l}\text { Evet } \\
\text { Hayır }\end{array}$ & $\begin{array}{l}37 \\
63\end{array}$ & $\begin{array}{l}7,59 \pm 2,9 \\
10,54 \pm 4,1\end{array}$ & $\mathrm{t}=-3833$ & ,оoo \\
\hline \multicolumn{6}{|l|}{ Independent-Samples T Test } \\
\hline Beden Kitle İndeksi & $\begin{array}{l}18,5-24,9 \\
25-29,9 \\
\geq 30\end{array}$ & $\begin{array}{l}13 \\
46 \\
41\end{array}$ & $\begin{array}{l}12,46 \pm 3,9 \\
8,96 \pm 4,2 \\
9,05 \pm 3,9\end{array}$ & $\mathrm{~F}=4,651$ & ,012 \\
\hline \multicolumn{6}{|l|}{ One-Way Anova Test } \\
\hline $\begin{array}{l}\text { Beslenme eğitimi alma } \\
\text { durumu }\end{array}$ & $\begin{array}{l}\text { Evet } \\
\text { Hayır }\end{array}$ & $\begin{array}{l}74 \\
26\end{array}$ & $\begin{array}{l}10,51 \pm 4,8 \\
6,42 \pm 3,1\end{array}$ & $\mathrm{t}=5,067$ & ,оoo \\
\hline $\begin{array}{l}\text { Beslenme eğitimini aldığı } \\
\text { kişi }\end{array}$ & $\begin{array}{l}\text { Doktor } \\
\text { Diyetisyen }\end{array}$ & $\begin{array}{l}16 \\
58\end{array}$ & $\begin{array}{l}8,44 \pm 3,3 \\
11,09 \pm 3,6\end{array}$ & $t=-2,641$ & ,010 \\
\hline $\begin{array}{l}\text { Beslenme eğitimini } \\
\text { uygulama durumu }\end{array}$ & $\begin{array}{l}\text { Evet } \\
\text { Hayır }\end{array}$ & $\begin{array}{l}35 \\
39\end{array}$ & $\begin{array}{l}12,97 \pm 3,1 \\
8,31 \pm 2,7\end{array}$ & $t=6,966$ & ,оoo \\
\hline \multirow{2}{*}{ İnsülin direnci testi } & Yapıldı & 66 & $10,02 \pm 4,1$ & \multirow{2}{*}{$t=2,020$} & \multirow{2}{*}{, $\mathbf{0 4 6}$} \\
\hline & Yapılmadı & 34 & $8,35 \pm 3,6$ & & \\
\hline \multirow{2}{*}{ İnsülin direnci değerleri } & Normal $(<2,5)$ & 10 & $12,60 \pm 4,3$ & \multirow{2}{*}{$t=2,261$} & \multirow{2}{*}{, $\mathbf{0 2 7}$} \\
\hline & Yüksek (> 2,5) & 56 & $9,55 \pm 3,8$ & & \\
\hline
\end{tabular}




\begin{tabular}{|c|c|c|c|c|c|}
\hline \multicolumn{6}{|l|}{ Independent-Samples T Test } \\
\hline Kan şekerini ölçme sıklığı & $\begin{array}{l}\text { Günlük } \\
\text { Haftada 1-2 kez } \\
\text { Düzensiz }\end{array}$ & $\begin{array}{l}20 \\
33 \\
47\end{array}$ & $\begin{array}{l}10,90 \pm 3,2 \\
11,15 \pm 4,1 \\
7,64 \pm 3,4\end{array}$ & $\mathrm{~F}=11,24$ &, $\mathbf{0 0 0}$ \\
\hline \multicolumn{6}{|l|}{ One-Way Anova Test } \\
\hline \multirow{2}{*}{$\begin{array}{l}\text { Son ölçülen tokluk kan } \\
\text { şekeri }\end{array}$} & $<200 \mathrm{mg} / \mathrm{dl}$ & 62 & $10,13 \pm 4,3$ & \multirow{2}{*}{$\mathrm{t}=2,235$} & \multirow{2}{*}{, $\mathbf{0 2 8}$} \\
\hline & $>200 \mathrm{mg} / \mathrm{dl}$ & 38 & $8,34 \pm 3,1$ & & \\
\hline \multirow{2}{*}{ Son ölçülen HbA1C değeri } & $<6,5$ & 24 & $10,96 \pm 4,8$ & \multirow{2}{*}{$t=2,182$} & \multirow{2}{*}{, $\mathbf{0 3 2}$} \\
\hline & $>6,5$ & 76 & $8,97 \pm 3,6$ & & \\
\hline \multicolumn{6}{|l|}{ Independent-Samples T Test } \\
\hline \multirow{4}{*}{ Diyabet tedavi şekli } & Tibbi beslenme tedavisi & 11 & $9,45 \pm 5,6$ & \multirow{4}{*}{$\mathrm{F}=3,709$} & \multirow{4}{*}{, 014} \\
\hline & $\begin{array}{l}\text { Tıbbi beslenme tedavisi + Oral } \\
\text { antidiyabetik }\end{array}$ & 34 & $11,12 \pm 3,8$ & & \\
\hline & $\begin{array}{l}\text { Tibbi beslenme tedavisi + } \\
\text { İnsülin }\end{array}$ & 36 & $8,69 \pm 3,3$ & & \\
\hline & $\begin{array}{l}\text { Tibbi beslenme tedavisi + Oral } \\
\text { antidiyabetik + İnsülin }\end{array}$ & 19 & $7,89 \pm 3,3$ & & \\
\hline \multicolumn{6}{|l|}{ One-Way Anova Test } \\
\hline \multirow{2}{*}{$\begin{array}{l}\text { Diyabet } \\
\text { komplikasyonlarını bilme } \\
\text { durumu }\end{array}$} & Evet & 58 & $10,29 \pm 3,8$ & \multirow[b]{2}{*}{$t=2,573$} & \multirow[b]{2}{*}{, 012} \\
\hline & Hayır & 42 & $8,28 \pm 3,8$ & & \\
\hline \multirow{2}{*}{$\begin{array}{l}\text { Düzenli HbA1C testi } \\
\text { yaptırma durumu }\end{array}$} & Evet & 64 & $10,76 \pm 3,9$ & \multirow{2}{*}{$\mathrm{t}=4,925$} & \multirow{2}{*}{, $\mathbf{0 0 0}$} \\
\hline & Hayır & 36 & $7,11 \pm 2,8$ & & \\
\hline \multirow{2}{*}{ Diyabetik ayak } & Biliniyor & 42 & $10,40 \pm 3,6$ & \multirow{2}{*}{$t=2,087$} & \multirow{2}{*}{, $\mathbf{0 3 9}$} \\
\hline & Bilinmiyor & 58 & $8,76 \pm 4,1$ & & \\
\hline
\end{tabular}

Ort: Ortalama, SS: Standart sapma

Çalışmada diyabet süresi, ailede diyabet öyküsü bulunma durumu ve son ölçülen açlık kan şekeri değeri soruları ile beslenme bilgi düzeyleri arasında anlamlı bir farklılık saptanmadı (p>,05). Aynı zamanda düzenli kolesterol, göz muayenesi ve kalp, böbrek kontrollerini yaptıranların yaptırmayanlara göre beslenme bilgi düzeyleri arasında anlamlı bir farklılık bulunmadı ( $>$ >,05).

\section{Tartışma}

Diyabet dünyada ve ülkemizde görülme sıklığı artan, ciddi komplikasyonları olan, ekonomik açıdan hasta ve yakınlarını zorlayan önemli bir sağlık sorunudur. Diyabetli hastaların beslenme bilgi düzeylerinin artırılması hastalığı iyi yönetmelerini sağlayan, hastaneye yatışları, diyabetin komplikasyonlarını ve mortaliteyi azaltan bir faktördür. $\mathrm{Bu}$ 
çalışmanın amacı diyabet polikliniklerine başvuran hastaların beslenme bilgi düzeylerini belirlemektir.

$\mathrm{Bu}$ araştırmada diyabetli hastaların beslenme bilgi puan ortalaması 9,45 $\pm 3,96$ 'tir (Tablo.3). Yapılan başka bir çalışmada; Diyabet Derneği’ne bağlı 88 diyabet hastasının 44'üne beslenme eğitimi verilmiş, diğer 44 kişilik gruba beslenme eğitimi verilmemiştir. Beslenme öncesi deney ve kontrol grubu hastaların bilgi düzeylerinin orta düzeyde olduğu tespit edilmiştir ${ }^{12}$. Fitzgerald ve ark., (2008) Tip 2 diyabetli olanlar ve olmayanların beslenme bilgilerini de değerlendirdikleri çalışmada; Tip 2 diyabetli grubu oluşturan bireylerde özellikle bir diyetisyen veya diyabet eğiticisi görenlerin beslenme bilgi puanlarının daha yüksek olduğunu saptamışlardır. ${ }^{13}$. Thewjitcharoen ve ark., (2018) hastanede takipli toplam 213 Tip 2 diyabetli hastaların beslenme bilgi skorlarının orta düzeyde olduğunu bulmuşlardır ${ }^{14}$. Diyabet hastalığında takipli olup, kurumun verdiği eğitimi alanların beslenme bilgi düzeylerinin orta düzeyde olduğ $\mathrm{u}^{14,15}$, ek olarak verilen eğitimlerin bilgi düzeyini $\operatorname{arttırdı} \breve{g ̆}_{1}{ }^{2}$ çalışmalarla desteklenmiştir. $\mathrm{Bu}$ araştırmada da diyabet polikliniğinde takipli hastaların beslenme bilgi düzeylerinin orta düzeyde olduğu ve verilen eğitimlerle beslenme bilgi düzeylerinin artırılabileceği düşünülmektedir. Diğer çalışma sonuçlarını destekler niteliktedir.

Araştırmada yaş aralığı 35-44 olan hastaların diyabetle ilgili beslenme bilgi düzeylerinin daha yüksek olduğu saptanmıştır (p<,05) (Tablo 4). Yaş aralığı 35-44 olan hastaların eğitim durumu incelendiğinde \%41,2'sinin üniversite mezunu olduğu tespit edilmiştir. $\mathrm{Bu}$ yaş grubu hastalarda eğitim durumunun yüksek olması sebebiyle beslenme bilgi düzeylerinin yüksek olduğu düşünülmektedir.

Araştırmada eğitim ve gelir durumu düşük olan hastaların beslenme bilgi düzeylerinin düşük olduğu saptanmıştır ( $\mathrm{p}<, 01$ ) (Tablo 4). Tip 2 diyabetli hastalarda diyabetle ilgili beslenme bilgilerinin ve diyet uyumunun değerlendirildiği bir çalışmada, eğitim ve gelir durumu düşük olan hastaların düşük beslenme bilgilerine sahip olduğu tespit edilmiştir ${ }^{16}$. Tip 2 diyabetin gelişmesinde sosyoekonomik durumun önemli rol oynadığı, diyabet görülme sıklığının eğitim seviyesi ve geliri düşük olanlarda daha fazla görüldüğü bildirilmektedir ${ }^{17,18}$. Eğitim durumu düşük olan hastalarda eğitim verilirken kullanılan öğretim tekniklerin yeterli olmaması beslenme bilgi düzeylerinin düşük olmasına neden olabilir. Eğitimlerin görsel, uygulamalı ve soru-cevap öğretim tekniklerinin kullanılarak yapılması diyabetle ilgili beslenme bilgi düzeylerini artırabilir. Çalışmada geliri düşük 
olan hastaların beslenme bilgi düzeylerinin düşük olmasının nedeni, yeterli geliri olmayan hastaların takiplerine düzenli gidememeleri ve bu sebeple kurumun verdiği eğitimden faydalanamamaları olabilir.

Çalışmada BKİ normal olan hastaların beslenme bilgi düzeyleri fazla kilolu ve obez hastalara göre daha yüksekti ( $\mathrm{p}<, 01$ ) (Tablo 5). Diyabetli hastaların beslenme bilgilerinin ve diyet alışkanlıklarının değerlendirildiği bir çalışmada belirledikleri popülasyonda fazla kilolu ve obez hastaların daha fazla olduğu ve beslenme bilgilerinin, diyet alışkanlıklarının zayıf olduğu saptandı ${ }^{19}$. Başka bir çalışmada Tip 2 diyabetli hastalarda beslenme bilgi puanı ve BKİ arasında ters korelasyon olduğunu, BKİ arttıkça beslenme bilgi puanlarının azaldığını tespit etmişlerdir²o. Breen ve ark. (20l5) düşük beslenme bilgisine sahip Tip 2 diyabetli hastaların yüksek glisemik indeksi olan diyete sahip olduklarını belirlemişlerdir²1. Beslenme bilgi düzeyleri düşük olan hastalar doğru beslenme alışkanlıklarına sahip olmadıkları için BKI’lerinin yüksek olması beklenen bir sonuçtur.

Çalışmada düzenli insülin direnci testi, kan şekeri takibi, HbA1C testi yaptıranların, diyabet komplikasyonlarını ve diyabetik ayak hakkında bilgi sahibi olanların bilgi düzeylerinin daha yüksek olduğu saptandı (sırasıyla; $\mathrm{p}<, 05 ; \mathrm{p}<, 001, \mathrm{p}<, 001$ ) (Tablo 5). Tip 1 ve Tip 2 diyabetli hastalarda beslenme bilgileri konusunda farkındalıklarının ve kan şekeri izleme sıklığının araştırıldığı çalışmada, hastaların çoğunun orta düzeyde bilgi sergiledikleri ve her gün Tip 2 diyabetli hastaların kan şekerlerini en az 1-2 kez kontrol ettiği belirlendi. Fakat aynı araştırmada katılımcıların yaklaşık yarısının HbA1C testini düzenli yaptırmadıkları ve bu grubu ağırlıklı olarak Tip 2 diyabetli hastaların oluşturduğu bulundü5 ${ }^{15}$ Çalışmalarda Tip 2 diyabetli hastaların beslenme bilgi düzeyleri artırıldıkça takiplerini daha düzenli yaptırdıkları saptanmıştır ${ }^{15,22}$. Araştırmada hastaların beslenme bilgi düzeylerinin orta seviyede olması sebebiyle bazı kontrollerini düzenli yaptırmadıkları, bilgi düzeyleri artırıldıkça takiplerini daha düzenli yapacakları düşünülmektedir. Tip 2 diyabetli hastalara entegre edilmiş sürekli eğitimin verilmesi hastalıkla ilgili tetkiklerin düzenli yapılmasını ve komplikasyonlarla ilgili daha iyi bilgi sahibi olmalarını sağlayacaktır.

Araştırmada insülin direnci değeri normal, son ölçülen tokluk kan şekeri $200 \mathrm{mg} / \mathrm{dl}$ 'nin altında ve HbA1c değeri \% 6,5 altındaki hastaların beslenme bilgi düzeyleri daha yüksektir ( $\mathrm{p}<, 05)$ (Tablo 5). Diyabetik hastaların beslenme bilgi düzeylerinin metabolik 
kontrolle ilişkisinin incelendiği bir çalışmada, bilgi düzeyi orta ve yüksek olan hastaların HbA1c değerlerinin daha düşük olduğu ortaya konulmuştur ${ }^{23}$. Hastaların diyabet ile ilgili beslenme bilgi düzeyi metabolik kontrolü etkilemektedir ${ }^{24,25}$. Tip 2 diyabetli hastaların diyabetle ilgili beslenme bilgilerini artırmak hastaların metabolik kontrolü sağlamalarını ve yaşam kalitelerini de arttırmayı sağlayacaktır.

\section{Sonuç}

Araştırmada, diyabetli hastaların bilgi düzeylerinin orta düzeyde olduğu belirlendi. Beslenme eğitimi almanın, eğitiminin diyetisyen tarafından verilmesinin ve alınan bu eğitimin hastalar tarafından uygulanmasının beslenme bilgi düzeylerini artırdığı görüldü. Beden Kitle İndeksi normal olan, insülin direnci testini yaptıran, kan şeker takiplerini düzenli yapan, düzenli HbA1c testini yaptıran, bu test sonuçları normal değerlerin altında olan, diyabet komplikasyonlarını ve diyabetik ayak hakkında bilgi sahibi olan hastaların beslenme bilgi düzeylerinin daha yüksek olduğu saptandı. Diyabetli hastalara beslenme eğitiminin verilmesi, hastaların beslenmede nelere dikkat etmesi gerektiğini, dikkat etmediği takdirde ileride yaşayabileceği sorunları bilmesini ve bu sorunların takibi için tetkiklerini yaptırması gerektiği bilincini oluşturmaktadır. Bu araştırma sonucunda; beslenme eğitiminin beslenme bilgi düzeyini etkilediği ve hastalarda doğru beslenme davranışları oluşturarak, hastalığı iyi yönettiği sonucuna varılmıştır. Diyabet polikliniklerinde Tip 2 diyabetli hastalara entegre ve sürekli eğitimin verilmesi önerilmektedir.

\section{KAYNAKLAR}

1. Juanola Falgarona M, Salas Salvadó, J, Ibarrola Jurado N, et al. Effect of the glycemic index of the diet on weight loss, modulation of satiety, inflammation, and other metabolic risk factors: a randomized controlled trial. American Journal of Clinical Nutrition. 2014;100(1):27-35.

2. Rouhani MH, Salehi-Abargouei A, Azadbakh L. Effect of glycemic index and glycemic load on energy intake in children. Nutrition. 2013;29(9):1100-1105.

3. World Health Organization. Global Report on Diabetes. https://apps.who.int/iris/bitstream/handle/10665/204871/9789241565257 eng. pdf?sequence=1. Yayınlanma tarihi 2016. Erişim tarihi 11 Mayıs 2021. 
4. Hacettepe Üniversitesi Sağlık Bilimleri Fakültesi Beslenme ve Diyetetik Bölümü. Türkiye Beslenme ve Sağlık Araştırması 2010: Beslenme Durumu ve Alışkanlıklarının Değerlendirilmesi Sonuç Raporu. Sağlık Bakanlığı Sağlık Araştırmaları Genel Müdürlüğü. Ankara: Sağlık Bakanlığı; 2014.

5. Sayalsan A. Sağlıklı beslenme açısından gıdaların glisemik indeksi. Gıda. 2005;10(1):84-91.

6. Tavani A, Basetti C, Negri E. Carbohydrates, dietary glycemic load and glycemic index and risk of acute myocardial infarction. Heart. 2003;89:722-726.

7. Vrolix R, Van Meijl LEC, Mensink RP. The metabolic syndrome in relation with the glycemic index and the glycemic load. Physiology Behavior. 2008;94(2):293-299.

8. Mercanlıgil SM. Kalp Damar Hastalıklarında Beslenme Önerileri. In: VI. Uluslararası Beslenme ve Diyet Kongresi; Nisan 2-6, 2008; Antalya, Türkiye.

9. Arvidsson-Lenner R, Asp N.D, Axelsen M. Glycemic index. Scandinavian Journal of Nutrition. 2004;48(2):84-95.

10. Çiftçi H, Akbulut G, Yıldız E. Mercanlıgil SM. Kan Şekerini Etkileyen Besinler. 1.baskı. Ankara: Klasmat Matbaacılı; 2008.

11. Akal Y. E. Glisemik İndeks. In: VI. Uluslararası Beslenme ve Diyet Kongresi; Nisan 2-6, 2008; Antalya, Türkiye.

12. Sharifirad G, Entezari MH, Kamran A, Azadbakht L. The effectiveness of nutritional education on the knowledge of diabetic patients using the health belief model. J Res. Med. Sci. 2009;14(1):1-6.

13. Fitzgerald N, Damı G, Segura-pérez S, Pérez-escamılla R. Nutrition knowledge, food label use, and food intake patterns among latinas with and without Type 2 Diabetes. Journal of the American Dietetic Association. 2008;108(6):960-967.

14. Thewjitcharoen Y, Chotwanvirat P, Jantawan A, et al. Evaluation of dietary intakes and nutritional knowledge in Thai patients with Type 2 Diabetes Mellitus. Hindawi Journal of Diabetes Research. 2018;1-11.

15. Ruszkiewicz K, Jagielski P, Traczyk I. Glycaemic control and awareness among diabetic patients of nutrition recommendations in diabetes. Rocz Panstw Zakl Hig. 2020;71(2):191-196.

16. Han1 Yixian C, Chan Boon CG, Lim SL, et al. Diabetes-related nutrition knowledge and dietary adherence in patients with Type 2 diabetes mellitus: a mixed-methods exploratory study. Proceedings of Singapore Healthcare. 2020;1-10. 
17. Bird Y, Lemstra M, Rogers M, Moraros J. The relationship between socioeconomic status/income and prevalence of diabetes and associated conditions: a crosssectional population-based study in Saskatchewan, Canada. International Journal for Equity in Health. 2015;14(93):1-8.

18. Sami W, Ansari T, Buttc NS, Ab Hamid Rashid M. Effect of diet on Type 2 diabetes mellitus: A review. International Journal of Health Sciences. 2017;11(2):65-71.

19. Olatona FA, Airede CA, Aderibigbe SA, Osibogun A. Nutritional knowledge, dietary habits and nutritional status of diabetic patients attending teaching hospitals in Lagos, Nigeria. Journal of Community Medicine and Primary Health Care. 2019;31(2):90-103.

20. Sami W, Alabdulwahhab KM, Ab Hamid Rashid M, Alasbali TA, Al Alwadani F, Ahmad MS. Dietary knowledge among adults with Type 2 diabetes Kingdom of Saudi Arabia. Int. J. Environ. Res. Public Health. 2020;17(858):1-8.

21. Breen C, Ryan M, Gibney MJ, O’Shea D. Diabetes-related nutrition knowledge and dietary intake among adults with Type 2 Diabetes. British Journal of Nutrition. 2015;114:439-447.

22. Wang H, Song Z, Ba Y, Zhu L, Wen Y. Nutritional and eating education improves knowledge and practice of patients with type 2 diabetes concerning dietary intake and blood glucose control in an outlying city of China. Public Health Nutrition. 2013;17(10),2351-2358.

23. Özdemir M, Aksoydan E, Çakır RE, Coşkun Y, Kocamış RN. Diyabetik hastaların beslenme alışkanlıkları ve bilgi düzeylerinin metabolik kontrolle ilişkisinin değerlendirilmesi. Başkent Üniversitesi Sağlık Bilimleri Fakültesi Dergisi. 2016;1(2):1-17.

24. Miller CK, Edwards L, Kissling G, Sanville L. Nutrition education improves metabolic outcomes among older adults with diabetes mellitus: results from a randomized controlled trial. Preventive Medicine. 2002;34:252-259.

25. Malekzadeh J, Pourali S, Behroozpour A, Amirian M, Malekzadeh F. Metabolic control, nutrition knowledge, attitude and practice in non-insulindependent diabetic patients from Kohgiluyeh and Boyer-ahmad province, southwest of Iran. Nutrition and Food Sciences Research. 2016;3(3):3-10. 